\title{
Wittgenstein and the Dream Hypothesis
}

\author{
Avrum Stroll
}

Received: 4 January 2009 /Revised: 7 February 2009 / Accepted: 16 March 2009 /

Published online: 29 April 2009

(C) The Author(s) 2009. This article is published with open access at Springerlink.com

\begin{abstract}
The paper deals with Wittgenstein's treatment of radical skepticism. He holds from his earliest work to his last that skepticism is senseless and therefore no rebuttal, such as G.E. Moore offered, is necessary.
\end{abstract}

Keywords Wittgenstein $\cdot$ Radical skepticism

Since the time of the Greeks, radical scepticism in various forms has been regarded as a main threat by those who are proponents of certainty, as Wittgenstein was in $O n$ Certainty. From antiquity to the present, the attempts to neutralize such threats have been largely regarded as unsuccessful. But the writings of Wittgenstein mark a new development in defusing this deflationary posture. Unlike most philosophers who have assumed that scepticism represents a coherent position that demands a responsible rebuttal, Wittgenstein emphasized that it was senseless, and required no formal refutation, especially of the sort that Moore tried to give in "Proof of an External World." In 6.51 of the Tractatus, his earliest publication, he uses the word "unsinn" to describe radical scepticism, and in entry 3.83 in On Certainty, his last notebook, he describes it as "sinnlos." However, the reasoning in support of his dismissal of scepticism differs over time, a topic that because of its complexity, I shall by-pass in this essay. ${ }^{1}$ For the exegete, however, there are two matters that are worth immediate expatiation. The first is that Wittgenstein frequently fails to specify what form of scepticism he is considering. This is true of both the Tractatus and On Certainty. In the former work, he writes:

Scepticism is not irrefutable but palpably senseless, if it would doubt where a question cannot be asked.

For doubt can only exist where there is a question; a question only where there is an answer, and this only where something can be said. (6.51)

\footnotetext{
${ }^{1}$ For a more extensive exploration of his treatment of general scepticism, see my books, Moore and Wittgenstein on Certainty (Oxford: Oxford U. Press, 1994), and Wittgenstein (Oxford: One World Press, 2002).
}

A. Stroll $(\bowtie)$

University of California, San Diego, USA

e-mail: astroll@ucsd.edu 
This citation not only refers to scepticism without mentioning any precise or definite form of that attitude, but it also rests on the famous showing and saying distinction. At TLP 4.1212, he writes: "What can be shown cannot be said." For the early Wittgenstein, the only things that can be said are the propositions of natural science (TLP 6.53). A limited number of things can only be shown: solipsism, a thinking, willing self, and the philosophical I, among them. Although he does not directly state this, the implication of these remarks is, presumably, that if something can be said, it cannot be shown.

We find the same lack of specificity in some of the key entries in On Certainty:

It would be as if someone were looking for some object in a room; he opens a drawer and doesn't see it there; then he closes it, waits, and opens it once more to see if perhaps it isn't there now, and keeps on like that. He has not learned to look for things....He has not learned the game that we are trying to teach him. (OC 315)

In this passage, the contrast Wittgenstein is working with is between doubts, that in principle can be settled, and those which cannot. Some commentators have also designated this contrast as being between "philosophical" and "everyday" doubt, a distinction that is indeed found in On Certainty ${ }^{2}$.

The situation is completely different with respect to the second matter I mentioned earlier. Without abandoning the idea that radical scepticism is senseless, Wittgenstein shifted gears and in his later writings — those that Danièle MoyalSharrock has called "the Third Wittgenstein," meaning by that term all of the writings he composed after Part I of the Investigations - he began to discuss the Dream Hypothesis of Descartes, that is, a specific form of scepticism. We can thus distinguish between his treatments of an unspecified and quite general form of scepticism and something more specific, namely, the Dream Hypothesis.

In order to see how Wittgenstein deals with Cartesian doubt, it will be useful to present a segment containing that argument. Here is the segment, taken from Meditation I:

Though this be true, I must nevertheless here consider that I am a man, and that, consequently, I am in the habit of sleeping, and representing to myself in dreams those same things, or even sometimes others less probable, which the insane think are presented to them in their waking moments. How often have I dreamt that I was in these familiar circumstances, that I was dressed, and occupied this place by the fire, when I was lying undressed in bed? At the present moment, however, I certainly look upon this paper with eyes wide awake; the head which I now move is not asleep; I extend this hand consciously and with express purpose, and I perceive it; the occurrences in sleep are not so distinct as all this. But I cannot forget that, at other times I have been deceived in sleep by similar illusions; and, attentively considering those cases, I perceive so clearly that there exist no certain marks by which the state of waking can ever be distinguished from sleep, that I feel greatly astonished; and in amazement I almost persuade myself that I am now

\footnotetext{
$\overline{{ }^{2} \text { For examples, see Wittgenstein }}$ and Moore on Certainty, 111, 116-117, 134-136, 140, and 179-180.
} 
dreaming. Let us suppose, then, that we are dreaming, and that all these particulars - namely, the opening of the eyes, the motion of the head, the forth- putting of the hands - are merely illusions; and even that we really possess neither an entire body nor hands. (Descartes 1955, 90-91)

It will be noted that the key to the argument lies in the supposition that dream and waking states cannot be distinguished. As Descartes says in the preceding passage: "there exist no certain marks by which the state of waking can ever be distinguished from sleep." Some philosophers have challenged this assumption, arguing that dream states lack the kind of coherence that normal waking experience exhibits. But this is not the thrust of Wittgenstein's objection. It is rather that he regards the statement that "I may be dreaming," if taken literally, as Descartes does, to be a form of nonsense. We shall see later why this is a deeper objection than anything anyone else had previously suggested.

It is interesting to speculate on why Wittgenstein turned from the generalized form of scepticism which we find in TLP and in numerous places in OC to the Dream Hypothesis. My own suggestion is that he regarded it as the deepest and most powerful version of radical scepticism. But this construal, of course, is a matter of sheer speculation since there is nothing in any of the Third Wittgenstein texts that gives us reliable information about his actual motivation.

Still, the question is worth thinking about, since the last entry (676) in OC deals with that argument. Obviously he deemed the Dream conjecture to represent a serious challenge to his advocacy of certitude. The entry was inserted into the manuscript only 2 days before he died in 1951. It reads as follows:

"But even if in such cases, I can't be mistaken, isn't it possible that I am drugged?" If I am and if the drug has taken away my consciousness, then I am not now really talking and thinking. I cannot seriously suppose that I am at this moment dreaming. Someone who, dreaming says: "I am dreaming," even if he speaks audibly in doing so, is no more right than if he said in his dream "it is raining," while it was in fact raining. Even if his dream were actually connected with the noise of the rain. (OC 676)

It will be noted that the first sentence is in quotes. We can therefore attribute the question to an unnamed interlocutor (usually a traditional philosopher). The interlocutor is raising an objection that Wittgenstein will address in the rest of the citation. In order to understand the interlocutor's cavil, we have to look at the paragraph that immediately precedes OC 676. Wittgenstein is now speaking:

If someone believes that he has flown from America to England in the last few days, then I believe, he cannot be making a mistake.

And just the same if someone says that he is at this moment sitting at a table and writing. (OC 675).

It is clear that Wittgenstein thinks that the interlocutor fails to distinguish mistakes from mental disturbances. ${ }^{3}$ In the penultimate passage just quoted, and in entries 194

\footnotetext{
${ }^{3}$ See my discussion of the difference between these concepts in Readings of Wittgenstein's On Certainty, ed. by Danièle Moyal-Sharrock and William H. Brenner (Basingstoke: Palgrave, 2007), 36-41.
} 
and 195 of OC, Wittgenstein is drawing just such a distinction. It is the difference that he sometimes characterizes as being between a Fehler or Irrtum, and a Geistestgestörtheit. Occasionally, instead of "Geistestgestört" he uses the term "verrückt" There are other places in that notebook where a similar contrast is being drawn:

If someone supposed that all our calculations were uncertain and that we could rely on none of them (justifying himself by saying that mistakes (Fehler) are always possible) perhaps we would say he was crazy (verrückt) But can we say he is in error? (er sei in Irrtum?) (OC 217)

In the three places in the writings of the Third Wittgenstein that treat the Dream Hypothesis, (Zettel, 396, OC 383, and 676) there are no explicit arguments showing that the conception is senseless, but there are remarks that can be construed as submerged arguments to this effect. Let us look seriatim at these entries to see if we can explicate his reasoning. In OC 676 the interlocutor is suggesting that it is possible that one might be drugged, and in that case one may well be mistaken about whether or when he has traveled. A guiding presupposition underlying the interlocutor's objection is that the effect of drugging could render a person unable to know where he is or what is happening to him. Wittgenstein interprets the assumption more strongly than the interlocutor intends, that is, as implying that the drugged person is unconscious. His response is to insist that one who is unconscious is "not really talking and thinking." His point is that a person who is not talking and thinking is not making a sensible assertion. This idea rests on a familiar thesis in all of Wittgenstein's later writings, namely, that certain background and contextual conditions have to be satisfied if an utterance is to count as a statement. And one of these conditions is that the person must be awake if his utterances are to be significant. The condition is obviously unfilled if the person is asleep and dreaming. Wittgenstein's way of formulating this condition is to say that a sleeping person is neither talking nor thinking.

An exegete might be puzzled by Wittgenstein's idea that a person who utters a well-formed sentence while unconscious or dreaming is not really talking. It is more plausible to hold that an utterance made while a person who is asleep or unconscious is not thinking. But in OC 350 Wittgenstein explains what he means by saying that a person who is dreaming or unconscious is not really talking. In this passage, he may well be conflating talking (in the sense of uttering certain words) with significant speech. But in either case it is only when the context is appropriate that a particular remark, even if well formed grammatically, will count as significant. He gives an example in that entry of someone who blurts out a comment that is grammatically in order, and where, Wittgenstein says, we do not even know what language the person is speaking. I will not quote all of the lengthy passage, but at least enough of it to illustrate why he says the speaker is not talking. Its relevance to the Dream Hypothesis is immediate:

Similarly, someone who was entertaining the idea that he was no use any more might keep repeating to himself "I can still do this and this and this." If such thoughts often possessed him one would not be surprised if he, apparently out of all context, spoke such a sentence out loud. (But here I have already 
sketched a background, a surrounding, for this remark, that is to say given it a context). But if someone in quite heterogeneous circumstances, called out with the most convincing mimicry: "Down with him!," one might say of these words (and their tone) that they were a pattern that does indeed have familiar applications, but that in this case it was not even clear what language the man in question was speaking. I might make with my hand the movement I should make if I were holding a hand-saw and sawing through a plank; but would one have any right to call this movement sawing, out of all context? - (It might be something quite different!). (OC 350)

The embedded argument we find here is that the same words said in certain circumstances constitute a recognizable speech act, but said in others do not. As he says: "one might say of these words that they were a pattern that does indeed have familiar applications." For example, the words "I may be dreaming," uttered by someone who is awake, may have a sensible use in certain circumstances. Suppose that a person has just inherited a fortune from a recently deceased relative with whom the recipient was relatively unacquainted. The heir might use those words to express his astonishment at having received such an unexpected gift. That he has used those words to say something significant entails, for Wittgenstein, that he was awake when he uttered them. Wittgenstein in effect is asking: are there any circumstance in which he could use the words literally to mean that at the moment of speaking he might be asleep and dreaming? The answer for him is obviously "no." This is what he is emphasizing when he states in OC 676 that someone who, dreaming, is no more right than if he said in his dream "It is raining while it was in fact raining." The submerged argument in this entry when made explicit is that if someone did mean them in that way his utterance would be self-defeating, for it would entail that he was awake at the time he spoke. This is thus a case in which the necessary contextual circumstances for significance would have been absent, and nothing sensible (sinnvoll) would have been said. In such a case, Wittgenstein says, one would not be talking and certainly would not be thinking. We find a similar pattern of reasoning in OC 383 :

The argument "I may be dreaming" is senseless (sinnlos) for this reason: If I am dreaming, this remark is being dreamed as well-and indeed it is also being dreamed that these words have any meaning (diese Worte eine Bedeutung haben.)

In claiming that one who is sleeping is not "really talking or thinking," Wittgenstein is, in effect, contrasting the situation that a person is in who says "I may be dreaming," when normal background conditions are satisfied with someone who is asleep. The contrast is made most explicit in Zettel 396. Here Wittgenstein's remarks, usually couched in the form of questions, can be seen to present a serious of submerged arguments against the Dream Hypothesis. One simply has to rewrite the passage in the least invasive way to present his comments as arguments. In order to see what such a rewrite would look like, it is probably a good idea to present the passage in its entirety. This is how the original reads:

What would it be like for someone to tell me with complete seriousness that he (really) did not know whether he was dreaming or awake?- 
Is the following situation possible: Someone says "I believe I am now dreaming"; he actually wakes up soon afterwards, remembers that utterance in his dream and says: "So I was right!"-This narrative can surely only signify: Someone dreamt that he had said he was dreaming.

Imagine an unconscious man (anaesthetized, say) were to say "I am conscious"- should we say "He ought to know"?

And if someone talked in his sleep and said "I am asleep" should we say "He"s quite right"?

Is someone speaking untruth if he says to me "I am not conscious"? (And truth, if he says it while unconscious? And suppose a parrot says "I don't understand a word," or a gramophone "I am only a machine"?) (Zettel, 396)

This passage opens with a sarcastic remark: "What would it be like for someone to tell me with complete seriousness that he (really) did not know whether he was dreaming or awake?" It is clear that the question is rhetorical. The emphasis in Wittgenstein's query is on four words: "with complete seriousness" and "really". If we reconstruct Wittgenstein's thought here we find the beginning of the argument that follows in the rest of the paragraph. Wittgenstein thinks it quite absurd to suppose that a person speaking as he stresses, "with complete seriousness" would really not know whether he was dreaming or awake. The query is essentially a continuation of the idea that the Cartesian supposition is senseless. Most persons of common sense would wonder, if they attended a philosophical conference, at the lack of reality that such epistemological speculation evinces. For most normal persons, the question of whether they are asleep or awake never arises. They go to bed at night and wake up in the morning and proceed to go about their normal activities. To ask: "Are you sure you are really awake when you get up in the morning," would evoke disdain from them. For such persons, it would be an absurd question. In this respect, Wittgenstein is a man of common sense, rejecting as nonsense the philosophical tradition that takes the question seriously.

The remainder of entry 396 from Zettel falls into four parts, each of which contains a question from Wittgenstein. Each question can be reconstituted as an assertion and each assertion as part of an argument whose general structure I will bring out below. I shall comment on the four parts in order. Wittgenstein asks:

1. Is the following situation possible: Someone says "I believe I am now dreaming"; he actually wakes up soon afterwards, remembers that utterance in his dream and says: "So I was right!" This narrative can surely only signify: Someone dreamt that he had said he was dreaming

Wittgenstein's comment here anticipates what he said in OC 383. There it will be recalled he wrote:

The argument "I may be dreaming" is senseless for this reason: if I am dreaming, this remark is being dreamed as well-and indeed it is also being dreamed that these words have any meaning. 
As I mentioned above, Zettel consists of a series of clippings from writings he had not used in other notebooks but which he felt might be useable in the future. The latest datings we have of these clippings are August 1948, or about 3 years before the last OC entries. There is thus a difference between the two fragments. In OC Wittgenstein is much tougher; in Zettel 396, without abandoning his long standing idea that radical scepticism is senseless, he does try to give a context in which the remark: "I believe I am now dreaming," would make sense. He says:

This narrative can surely only signify: someone dreamt that he had said he was dreaming."

The context refers to what might happen in a dream state. The sleeper is uttering some words that he later remembers. But it is clear that Wittgenstein's further remark that the dreaming person upon awakening says "So I was right!" is a piece of nonsense. Any comment made by a sleeping person cannot be taken literally. So even this contextual concession does not affect his general thesis that if the person said those words while asleep they would be senseless.

2. Let us now turn to his second comment. Again it begins with a question:

Imagine an unconscious man (anaesthetized say) were to say "I am conscious"- should we say: "He ought to know."?

It is clear that Wittgenstein regards the remark by one who is unconscious as nonsense. The thrust of his question, when rewritten as an assertion, is not that the unconscious man is saying something that is palpably untrue in saying that he is conscious, but that any auditor should discount the remark as having significance. The idea that a person who is unconscious can say anything significant rests upon the assumption that such a person must be awake and must intend to make a positive or negative claim in order to say anything meaningful. It is obvious that if one is unconscious one cannot intend anything. The fact that one mutters a well-formed sentence must thus not be taken seriously. One might describe the utterance as a case of babbling. The fact that the words can be understood by an auditor, say a nurse or doctor, is irrelevant with respect to whether they can be regarded as making a meaningful assertion.

3. Wittgenstein reinforces this contention with his next question. He is now addressing the Dream Hypothesis directly:

And if someone talked in his sleep and said "I am asleep" should we say "He's quite right"?

The point he is making here is that "I am asleep," if said while a person is actually asleep and presumably dreaming, cannot be taken as significant. Wittgenstein's question: Should we say he's quite right? is sardonic. As I have suggested above, the question it expresses should be understood as making an affirmation, namely that to say he's "quite right," is to be disregarded in those circumstances. It is nonsense to think that a person who is asleep and hence not thinking or intending anything can utter a significant statement. The import of such a rewriting is to cast serious doubt 
on whether Descartes' depiction of his obsessive doubting makes sense. He says in Meditation I, it will be recalled:

Let us suppose, then that we are dreaming, and that all these particulars - namely, the opening of the eyes, the motion of the head, the forth-putting of the hands - are merely illusions and even that we really possess neither an entire body nor hands.

It is interesting and informative to compare Wittgenstein's approach to the Dream Scenario with Moore's. Moore was, of course, a distinguished philosopher in his own right; but Wittgenstein's understanding of the Dream Hypothesis exhibits a profundity that well eclipses Moore's. Unlike Moore who assumed that the Cartesian hypothesis had to be met with a counter-proof, Wittgenstein is cutting it off at its source by giving reasons why it does not make sense.

Moore realized when he was teaching at Cambridge and Wittgenstein was a student there that Wittgenstein's philosophical acumen was of a different order from his or any other philosopher's. He was correct in that evaluation. Wittgenstein was a genius and Moore an above average college professor with an exceptional gift for making subtle linguistic distinctions. To see how Moore rated himself in comparison to Wittgenstein we should reread his autobiography. In it, he describes their profoundly differing understandings of the peculiar nature of philosophical puzzles:

In 1912 I became acquainted with Wittgenstein. During the first year in which he was at Cambridge he attended my lectures on Psychology; but it was only during the next 2 years that I got to know him at all well. When I did get to know him, I soon came to feel that he was much cleverer at philosophy than I was, and not only cleverer, but also much more profound, and with a better insight into the sort of inquiry which was really important and best worth pursuing, and into the best method of pursuing such inquiries. I did not see him again, after 1914, until he returned to Cambridge in 1929; but when his Tractatus Logico-Philosophicus came out, I read it again and again, trying to learn from it. It is a book which I admired and do admire extremely. There is, of course, a great deal in it which I was not able to understand; but many things I thought I did understand, and found them very enlightening. When he came back to Cambridge in 1929 I attended his lectures for several years in succession, always with admiration ${ }^{4}$. How far he has influenced positively anything that I have written, I cannot tell; but he certainly has had the effect of making me very distrustful about many things which, but for him, I should have been inclined to assert positively. He has made me think that what is

\footnotetext{
${ }^{4}$ Despite the seriousness, and even solemnity, of much of Moore's writing, he had a robust and somewhat sly sense of humor. Here are two examples: When Wittgenstein returned to Cambridge, he enrolled as a PhD student, and submitted the Tractatus, which had been published seven years earlier, as his doctoral dissertation. Moore and Russell agreed to serve as examiners on his committee. According to Hermine Wittgenstein, Ludwig's sister, the exam seems to have been something of a farce. She says: "It consisted of the professors asking Ludwig to explain passages from his book." As one might have predicted, Wittgenstein passed the exam with flying colors. At its conclusion, Moore wrote to the Cambridge authorities: 'It is my personal opinion that Mr. Wittgenstein's thesis is a work of genius; but, be that as it may, it is certainly well up to the standard required for the Cambridge degree of Doctor of Philosophy'. Now a second example. In one of his essays, he mentions that the Duke of Bedford dreamed that he was speaking before the House of Lords and when the Duke woke up, he was.
} 
required for the solution of philosophical problems which baffle me, is a method quite different from any which I have ever used-a method which he himself uses successfully, but which I have never been able to understand clearly enough to use it myself. I'm glad to think that he is my successor in the Professorship at Cambridge. (Moore 1968, 33)

Moore's autobiography was published in 1942, not long after his career as a teacher at Cambridge had ended. He is characteristically frank and honest in acknowledging that Wittgenstein used a method for dealing with philosophical problems that he (Moore) was never able to understand clearly enough to use himself. Wittgenstein's treatment of the Dream Hypothesis is a good example of their differing approaches to such worries. Moore was, as I have said, a distinguished thinker by any standard. If a list of great British philosophers from Hobbes through Russell, were to be drawn up, Moore would obviously rank very high in that selection. But as our description of Wittgenstein's assessment of The Dream Hypothesis shows, Moore was no Wittgenstein.

The preceding quotations from Zettel illustrate the sort of moves that Wittgenstein makes against Moore's "Proof of an External World." The passages I have quoted contain implicit arguments that not only undermine Moore's assumption that "I may be dreaming," is sensible but that show that the Cartesian argument is also senseless. The implication to be drawn from Wittgenstein's implicit arguments is a powerful criticism of any attempt, such as Moore tries to develop, to provide a counterargument to scepticism. If the sceptic's position cannot be coherently stated, there is nothing that needs to be refuted. And indeed to offer a so-called "proof" by way of such a refutation is itself incoherent, since it mistakenly assumes that the Dream Hypothesis is a sensible conjecture. This is a mistake that Wittgenstein never made.

The passage from Zettel concludes with another question that can and should be rewritten as an affirmation. It says:

4. Is someone speaking untruth if he says to me "I am not conscious," (And truth, if he says it while unconscious)? And suppose a parrot says "I don't understand a word," or a gramophone "I am only a machine." (Zettel, 396).

Wittgenstein's examples here are particularly powerful. They make the point that a person who is unconscious is not intending to say anything and that accordingly no questions of truth or falsity arise. Wittgenstein's questions about what a person would say if unconscious have to be reconstituted as assertions if their full power is to be felt. All of these reworked assertions form part of a general argument that Wittgenstein never states in any of his later writings, but which I think bring out the force of his sarcastic questions. That argument - and I emphasize again that it cannot be found in any of the texts we now have-might be formulated as follows:

Insofar as X, a radical sceptic such as Descartes, wishes to make a certain kind of conceptual point, the utterance that $X$ uses to make it must be a genuine statement. Suppose X utters the sentence, "I may be dreaming." If X is in fact asleep and dreaming, the requirement of genuine statement-making is violated. For if $\mathrm{X}$ is in fact asleep and dreaming, his remark occurs as part of his dream. In that case, $\mathrm{X}$ is not really intending to make a claim about his present state of mind (or as 
Wittgenstein puts it, is not talking or thinking) and therefore his utterance is not a genuine assertion. It is not a genuine assertion because the background conditions for statement-making have not been satisfied. These conditions are that $\mathrm{X}$ be awake, be fully aware of what his words mean, and intend them to make an assertion. But if X is asleep, these criteria remain unfulfilled. Therefore, X's words are senseless when uttered in those circumstances; and because that is so, X's attempt to state, in the Dream Hypothesis, a radical form of scepticism lacks conceptual force. This does not mean that the same words, uttered in different circumstances, may not have an application. They can, but they cannot be used, with sense, by a person who is fully awake, to claim that he might at that very moment be asleep and dreaming.

This is a new specimen of reasoning. It shows the originality of Wittgenstein's thinking about an attitude that has bedeviled philosophy from its earliest beginnings to the present, and that many thinkers, convinced that we have both knowledge and certainty about the world, have tried to rebut. Wittgenstein's genius consisted, at least in part, in looking at this form of incessant doubt from a genuinely different standpoint. He is unquestionably right that such forms of radical scepticism cannot even be coherently formulated, and that any attempt to do so is palpable nonsense.

Open Access This article is distributed under the terms of the Creative Commons Attribution Noncommercial License which permits any noncommercial use, distribution, and reproduction in any medium, provided the original author(s) and source are credited.

\section{References}

Descartes, R. (1955) Descartes Selections, ed. Ralph M. Eaton, New York: Scribner's.

Moore, G. E. (1968) Autobiography. In The Philosophy of G.E. Moore. La Salle, Illinois: Open Court, 3rd Edition, 20-3. 